\title{
Kinetics and Mechanism of the Oxidation of Aliphatic Aldehydes by Benzimidazolium Dichromate
}

\author{
Pravesh Kumar, Dinesh Panday, and Seema Kothari* \\ Department of Chemistry, J N V University, Jodhpur 342 001, India
}

RECEIVED APRIL 21, 2010; REVISED NOVEMBER 13, 2010; ACCEPTED DECEMBER 27, 2010

\begin{abstract}
Kinetic and mechanistic studies of the oxidation of aliphatic aldehydes, (in organic non-aqueous solvents), were discussed with an emphasis of correlation of structure and reactivity. The reactions were of first order with respect to BIDC and hydrogen-ion. However, Michaelis-Menten type kinetics were observed with respect to aldehyde. The deuterium isotope effect for the oxidation of acetaldehyde $\left(k_{\mathrm{H}} / k_{\mathrm{D}}=6.36\right.$ at $\left.298 \mathrm{~K}\right)$ indicated an $\alpha-\mathrm{C}-\mathrm{H}$ bond cleavage in the rate-determining step. Based on kinetic data, analyses of the solvent effect and results of structure-reactivity correlation along with some nonkinetic parameters suggested a mechanism involving rate-determining oxidative decomposition of a aldehyde-BIDC complex via a cyclic transition state to give a carbocationic species through hydride-ion transfer from the aldehyde to the oxidant. (doi: 10.5562/cca1694)
\end{abstract}

Keywords: kinetics, oxidation, aliphatic aldehydes, benzimidazolium dichromate, mechanism

\section{INTRODUCTION}

Selective oxidation of organic compounds under nonaqueous conditions is an important transformation in synthetic organic chemistry. For this, a number of different chromium(VI) derivatives have been reported. ${ }^{1,2}$ In 1998, Meng et al. $^{3}$ reported a new $\mathrm{Cr}(\mathrm{VI})$ derivative benzimidazolium dichromate (BIDC). It is neither hygroscopic nor light sensitive, therefore, it is more stable and easily stored as compared to other $\mathrm{Cr}(\mathrm{VI})$ reagents. BIDC is reported ${ }^{3}$ to convert benzylic and allylic alcohols to corresponding carbonyl compounds in yield ranging from 75 to $98 \%$. We have been interested in the kinetics and mechanism of the oxidation by newer $\mathrm{Cr}(\mathrm{VI})$ derivatives. There seems to be only two reports available on the kinetic and mechanistic aspects of the oxidation by BIDC. ${ }^{4,5}$ These are published from our laboratory. In the continuation of our studies, we report here the kinetics of the oxidation of six aliphatic aldehydes viz. formaldehyde, acetaldehyde, propionaldehyde, butyraldehyde, 2-methylpropionaldehyde and chloroacetaldehyde by BIDC in dimethylsulphoxide (DMSO) as the solvent. The present investigation was undertaken, primarily to discuss the kinetic and mechanistic aspects along with structure-reactivity correlation in the oxidation reaction and secondly to compare the results with that of the oxidation of aliphatic aldehydes by other $\mathrm{Cr}(\mathrm{VI})$ complexes.

\section{EXPERIMENTAL}

\section{Materials}

BIDC was prepared by the reported method $^{3}$ and its purity was checked by an iodometric method. All the aldehydes were commercial products and were purified by the methods described earlier. ${ }^{6,7}$ Deuteriated acetaldehyde (MeCDO) was obtained from Sigma Chemicals. The solvents were purified by the reported methods. ${ }^{8}$ Amongst the solvents, $\mathrm{CS}_{2}$ is a flammable liquid and is toxic. Toluene p-sulphonic acid ( $\mathrm{TsOH})$ was used as a source of hydrogen ions.

\section{Product Analysis}

The product analysis was carried out under kinetic conditions. In a typical experiment, acetaldehyde $(0.1 \mathrm{~mol})$ and BIDC (0.01 mol) were made up to $100 \mathrm{ml}$ in DMSO in the presence of $1.0 \mathrm{~mol} \mathrm{dm}^{-3} \mathrm{TsOH}$. It was then kept in the dark for $c a .15-20 \mathrm{~h}$ to ensure completion of the reaction. It was rendered alkaline and evaporated to dryness under reduced pressure. The residue was acidified and extracted with ether $(3 \times 50 \mathrm{ml})$. The ether extract was dried with anhydrous magnesium sulfate and treated with thionyl chloride $(10 \mathrm{ml})$. The solvent was allowed to evaporate. Dry methanol $(7 \mathrm{ml})$ was added and $\mathrm{HCl}$ formed was removed in a current of dry

\footnotetext{
* Author to whom correspondence should be addressed. (E-mail: seemakothari23@gmail.com)
} 
Table 1. Stoichiometry of the oxidation of propionaldehyde by BIDC

\begin{tabular}{|c|c|c|c|}
\hline $10^{3}$ [BIDC] & $10^{3}$ [Aldehyde] & $10^{3}$ [Residual BIDC] & [Aldehyde] \\
\hline $\mathrm{mol} \mathrm{dm}^{-3}$ & $\mathrm{~mol} \mathrm{dm}^{-3}$ & $\mathrm{~mol} \mathrm{dm}^{-3}$ & [Consumed BIDC] \\
\hline 5.0 & 1.0 & 4.35 & 1.54 \\
\hline 5.0 & 2.0 & 3.65 & 1.48 \\
\hline 5.0 & 3.0 & 3.04 & 1.53 \\
\hline \multicolumn{4}{|c|}{ Mean $=1.52$} \\
\hline
\end{tabular}

air. The residue was dissolved in ether $(200 \mathrm{ml})$ and the ester content was determined colorimeterically as iron(III) hydroximate by the method of Hall and Schaefer. ${ }^{9}$ The yield of acetic acid was $89 \%$.

\section{Stoichiometry}

To determine the stoichiometry, BIDC $\left(0.005 \mathrm{~mol} \mathrm{dm}^{-3}\right)$ and aldehyde $\left(0.001 \mathrm{~mol} \mathrm{dm}^{-3}\right)$ were made up to $100 \mathrm{ml}$ in DMSO in the presence of $1.0 \mathrm{~mol} \mathrm{dm}^{-3} \mathrm{TsOH}$. The reaction was allowed to stand for $c a .20 \mathrm{~h}$ to ensure completion of the reaction. The residual BIDC was determined spectrophotometrically at $364 \mathrm{~nm}$. Several determinations, with different aldehydes using different concentrations showed that the stoichiometry is 3:2 i.e. 3 moles of aldehyde are consumed by 2 moles of oxidant. The results with propionaldehyde are presented in Table 1. BIDC thus acts as a 3-electron oxidant and is reduced to $\mathrm{Cr}(\mathrm{III})$.

\section{Spectral Studies}

UV-VIS spectra of (i) BIDC $\left(0.0003 \mathrm{~mol} \mathrm{dm}^{-3}\right)$ alone and (ii) of propionaldehyde $\left(1.35 \mathrm{~mol} \mathrm{dm}^{-3}\right)+$ BIDC $\left(0.0003 \mathrm{~mol} \mathrm{dm}^{-3}\right)$ were recorded on UV-VIS spectrophotometer (Model UV5704, ECIL). The solvent was DMSO. The concentration of $\mathrm{TsOH}$ used was 0.0005 mol dm ${ }^{-3}$ and temperature was $293 \pm 1 \mathrm{~K}$. The spectra of the reaction mixture (ii) was also recorded at different times till completion of reaction. For (i) the blank was the solvent and for (ii) the blank was a solution of propionaldehyde $\left(1.35 \mathrm{~mol} \mathrm{dm}^{-3}\right)$ in DMSO in the presence of $0.0005 \mathrm{~mol} \mathrm{dm}^{-3} \mathrm{TsOH}$. The time gap between the preparation of the reaction mixture and recording of spectrum (B) was $<30 \mathrm{~s}$.

\section{Kinetic Measurements}

Pseudo-first order conditions were attained by keeping a large excess (10 times or greater) of the aldehyde over the oxidant. The reactions were carried out at constant temperature $( \pm 0.1 \mathrm{~K})$. The solvent was DMSO, unless stated otherwise. The reactions were followed by monitoring the decrease in the concentration of BIDC at 364 $\mathrm{nm}$ for up to $80 \%$ of the reaction. The Beer's law is valid for BIDC within the concentration range used in our experiments. The pseudo-first order rate constant, $k_{\text {obs}}$, was evaluated from the linear $\left(r^{2}>0.995\right)$ plots of $\log$ [BIDC] vs. time. Duplicate kinetic runs showed that the rate constants were reproducible to within $\pm 3 \%$. In correlation analyses, we have used coefficient of determination $\left(R^{2}\right.$ or $\left.r^{2}\right)$, standard deviation (SD) and Exner's parameter, ${ }^{10} \Psi$, as the measures of the goodness of fit.

\section{RESULTS}

The rates and other experimental data were obtained for all the aldehydes. Since the results are similar, only representative data are reproduced here.

The oxidation of aliphatic aldehydes by BIDC resulted in the formation of the corresponding acid. The product analysis and the stoichiometry determination suggested the following overall reaction:

$$
\begin{aligned}
3 \mathrm{RCHO} & +2 \mathrm{Cr}_{2} \mathrm{O}_{7}^{-2}+22 \mathrm{H}^{+} \rightarrow \\
& \rightarrow 3 \mathrm{RCOOH}+2 \mathrm{Cr}^{+3}+11 \mathrm{H}_{2} \mathrm{O}+2 \mathrm{Cr}^{+6}
\end{aligned}
$$

\section{Test for Free Radicals}

The oxidation of an aldehyde by BIDC, in an atmosphere of nitrogen, failed to induce polymerization of acrylonitrile. In blank experiments, with the substrate absent, no noticeable consumption of BIDC was observed. The addition of acrylonitrile had no effect on the rate of oxidation (Table 2). To further confirm the absence of free radicals in the reaction pathway, the reaction was carried out in the presence of $0.05 \mathrm{~mol} \mathrm{dm}^{-3}$ of 2,6-di-t-butyl-4-methylphenol (butylated hydroxytoluene or BHT). It was observed that BHT was recovered unchanged, almost quantitatively.

\section{Rate Laws}

The reactions were found to be of first order with respect to BIDC. In individual kinetic runs, plots of log [BIDC] vs. time were linear $\left(r^{2}>0.995\right)$. Further, the pseudo-first order rate constants do not depend on the initial concentration of BIDC (Table 2). The order with respect to aldehyde was less than one (Table 2). A plot of $k_{\text {obs }} v s$. [aldehyde] is shown in Figure 1 (formaldehyde and chloroacetaldehyde were excluded because the rates are not comparable with other aldehydes). The 
Table 2. Rate constants for the oxidation of aldehydes (RCHO) by BIDC at $308 \mathrm{~K},\left[\mathrm{H}^{+}\right]=1.0 \mathrm{~mol} \mathrm{dm}^{-3}$

\begin{tabular}{|c|c|c|c|c|c|c|c|}
\hline \multirow{2}{*}{$\frac{[\mathrm{RCHO}]}{\mathrm{mol} \mathrm{dm}^{-3}}$} & \multirow{2}{*}{$\frac{10^{3}[\mathrm{BIDC}]}{\mathrm{mol} \mathrm{dm}^{-3}}$} & \multicolumn{6}{|c|}{$10^{3} \times k_{\mathrm{obs}} / \mathrm{s}^{-1}$} \\
\hline & & $\mathrm{H}$ & $\mathrm{Me}$ & Et & $\operatorname{Pr}$ & $\operatorname{Pr}^{\mathrm{i}}$ & $\mathrm{ClCH}_{2}$ \\
\hline 0.05 & 1.0 & 0.672 & 8.39 & 13.6 & 16.1 & 24.3 & 0.0300 \\
\hline 0.08 & 1.0 & 0.973 & 12.0 & 19.8 & 23.4 & 35.3 & 0.0435 \\
\hline 0.10 & 1.0 & 1.12 & 14.6 & 23.1 & 27.3 & 41.3 & 0.0514 \\
\hline 0.20 & 1.0 & 1.79 & 21.8 & 36.4 & 43.5 & 65.8 & 0.0793 \\
\hline 0.40 & 1.0 & 2.38 & 30.8 & 49.5 & 60.0 & 89.8 & 0.109 \\
\hline 0.60 & 1.0 & 2.76 & 34.8 & 57.0 & 68.9 & 104 & 0.126 \\
\hline 1.00 & 1.0 & 3.09 & 40.0 & 64.5 & 78.3 & 118 & 0.141 \\
\hline 0.10 & 0.5 & 1.17 & 15.0 & 22.6 & 27.0 & 42.0 & 0.0531 \\
\hline 0.10 & 0.8 & 1.21 & 13.9 & 23.5 & 26.4 & 39.9 & 0.0499 \\
\hline 0.10 & 2.0 & 1.15 & 14.5 & 21.8 & 28.0 & 43.1 & 0.0520 \\
\hline 0.10 & 3.0 & 1.12 & 14.9 & 23.0 & 26.9 & 42.9 & 0.0500 \\
\hline 0.10 & 5.0 & 1.20 & 15.3 & 21.9 & 25.9 & 41.0 & 0.0511 \\
\hline 0.05 & 1.0 & $0.681^{(\mathrm{a})}$ & $8.47^{(\mathrm{a})}$ & $13.0^{(\mathrm{a})}$ & $15.6^{(\mathrm{a})}$ & $24.5^{(\mathrm{a})}$ & $0.0317^{(\mathrm{a})}$ \\
\hline 0.08 & 1.0 & $0.968^{(\mathrm{a})}$ & $11.8^{(\mathrm{b})}$ & $20.5^{(\mathrm{b})}$ & $23.0^{(\mathrm{b})}$ & $35.0^{(\mathrm{b})}$ & $0.0429^{(\mathrm{b})}$ \\
\hline
\end{tabular}

(a) $c$ (acrylonitrile) $=0.001 \mathrm{~mol} \mathrm{dm}^{-3}$.

(b) $c$ (acrylonitrile $)=0.005 \mathrm{~mol} \mathrm{dm}^{-3}$

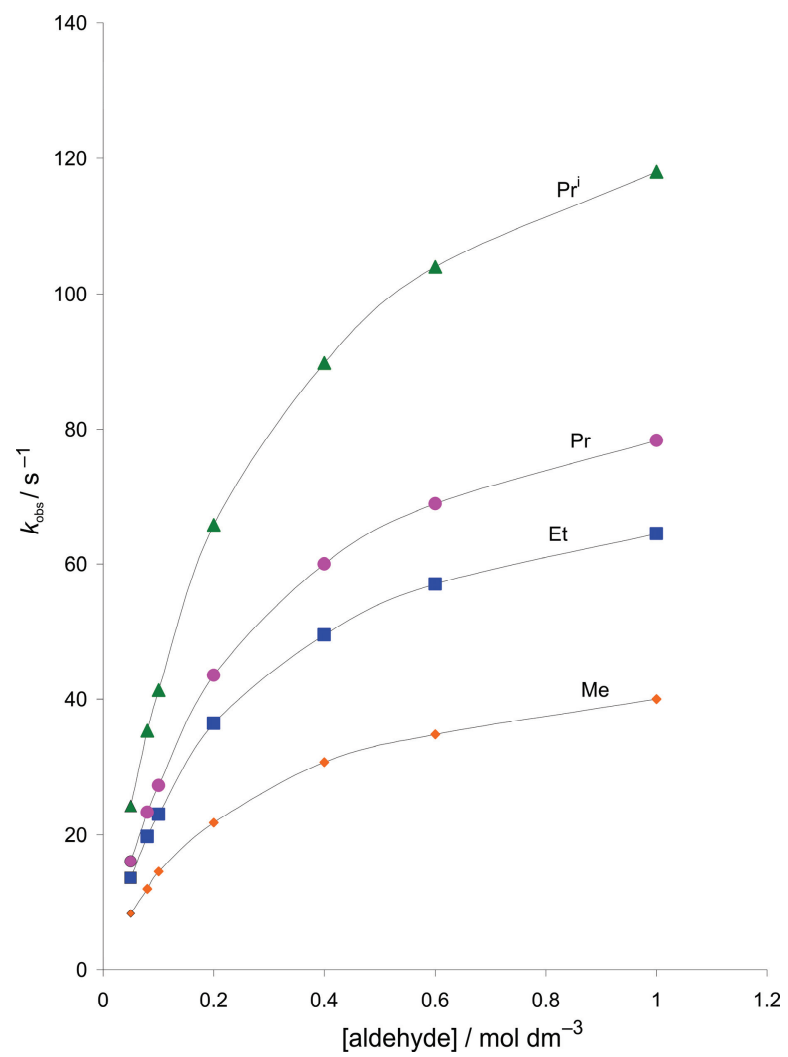

Figure 1. A plot of $10^{3} k_{\text {obs }} v s$. [aldehyde]. [BIDC] $=0.001$ mol dm${ }^{-3} ;\left[\mathrm{H}^{+}\right]=1.0 \mathrm{~mol} \mathrm{dm}{ }^{-3}$; temperature $308 \mathrm{~K}$.

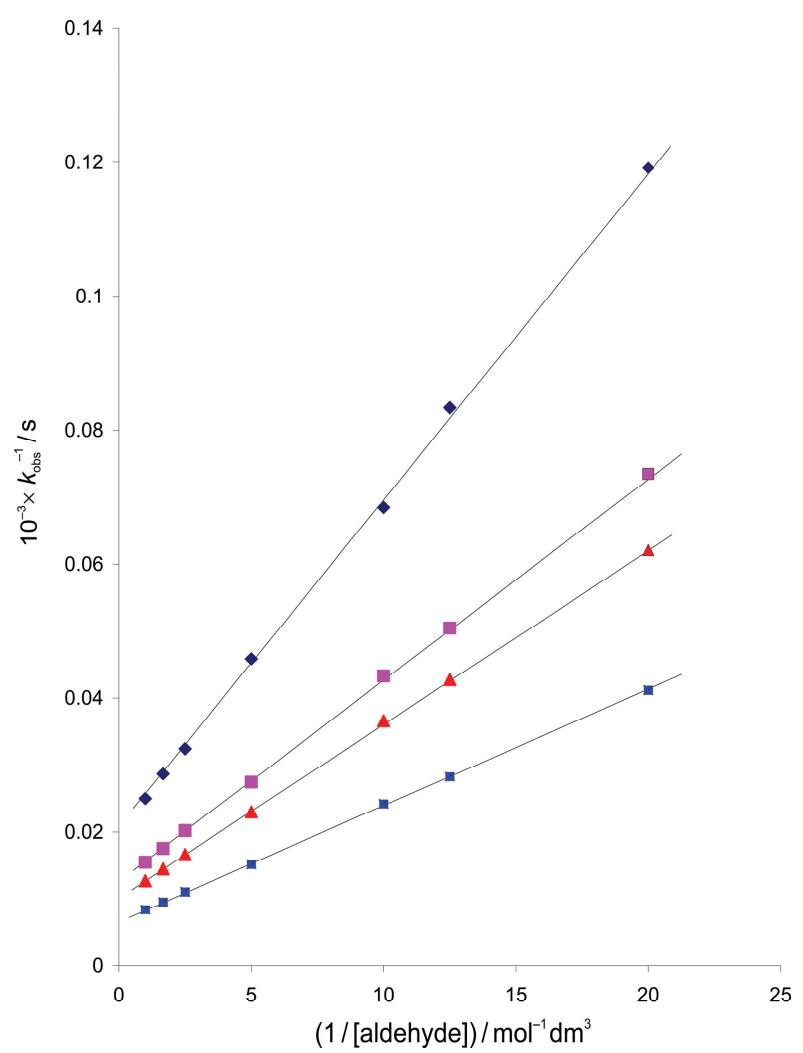

Figure 2. A plot of $10^{-3} 1 / k_{\text {obs }}$ vs. $1 /$ [aldehyde]. [BIDC] $=$ $0.001 \mathrm{~mol} \mathrm{dm}^{-3} ;[\mathrm{H}+]=1.0 \mathrm{~mol} \mathrm{dm}{ }^{-3}$; temperature $308 \mathrm{~K}$. 
downward curvature of the plots suggests the existence of a complex. A plot of $1 / k_{\text {obs }} v s$. 1/[aldehyde] was linear with an intercept on the rate ordinate (Figure 2). Thus, a Michaelis-Menten type kinetics were observed with respect to aldehyde. This leads to the postulation of following overall mechanism and rate law:

$$
\begin{gathered}
\text { Aldehyde }+ \text { BIDC } \stackrel{K}{\rightleftharpoons}[\text { Complex }] \\
{[\text { Complex }] \stackrel{k_{2}}{\longrightarrow} \text { Product }} \\
\text { Rate }=\frac{k_{2} K[\text { Aldehyde }][\text { BIDC }]_{t}}{1+K[\text { Aldehyde }]}
\end{gathered}
$$

or,

$$
\begin{aligned}
& \left(\text { Rate } /[\mathrm{BIDC}]_{t}\right)^{-1}=1 / k_{\mathrm{obs}}= \\
& 1 / k_{2} K[\text { Aldehyde }]+1 / k_{2}
\end{aligned}
$$

Here,

$$
[\mathrm{BIDC}]_{t}=[\mathrm{BIDC}]+[\text { Complex }]
$$

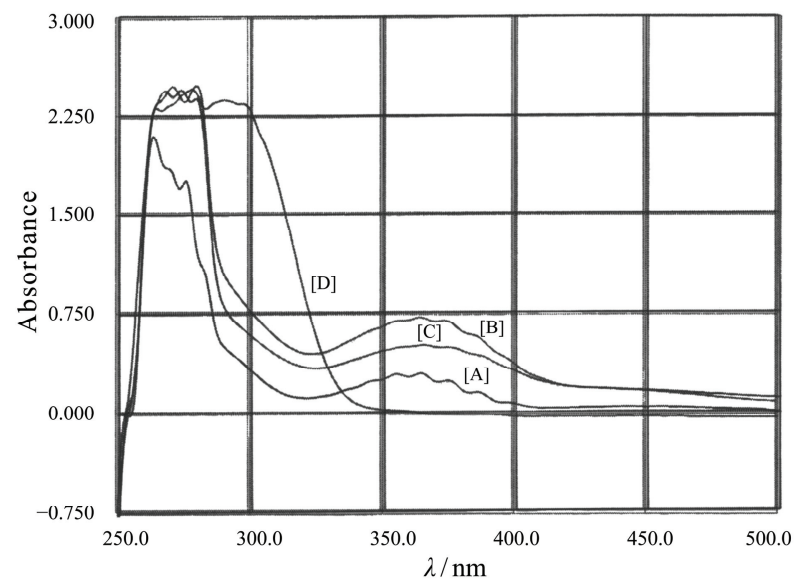

Figure 3. UV-VIS spectra of: (i) $[\mathrm{A}]-0.0003 \mathrm{~mol} \mathrm{dm}^{-3}$ BIDC; (ii) $[\mathrm{B}]-[\mathrm{A}]+1.35 \mathrm{~mol} \mathrm{dm}^{-3}$ propionaldehyde; (iii) [C] $-[\mathrm{B}]$ after $3600 \mathrm{~s}$; (iv) [D] - [B] on about completion of reactionSolvent - DMSO. $T=293 \pm 1 \mathrm{~K}$.

\begin{tabular}{|c|c|c|c|c|c|c|c|}
\hline \multirow{2}{*}{$\begin{array}{l}\text { Subst. } \\
\text { (R) }\end{array}$} & \multicolumn{4}{|c|}{$K / \mathrm{dm}^{3} \mathrm{~mol}^{-1}$} & \multirow{2}{*}{$\frac{\Delta H}{\mathrm{~kJ} \mathrm{~mol}^{-1}}$} & \multirow{2}{*}{$\begin{array}{c}\Delta S \\
\mathrm{~J} \mathrm{~mol}^{-1} \mathrm{~K}^{-1}\end{array}$} & \multirow{2}{*}{$\frac{\Delta G}{\mathrm{~kJ} \mathrm{~mol}^{-1}}$} \\
\hline & $298 \mathrm{~K}$ & $308 \mathrm{~K}$ & $318 \mathrm{~K}$ & $328 \mathrm{~K}$ & & & \\
\hline $\mathrm{H}$ & 4.89 & 4.27 & 3.69 & 3.31 & $-13.2 \pm 0.2$ & $-23 \pm 1$ & $-6.43 \pm 0.2$ \\
\hline $\mathrm{Me}$ & 4.71 & 4.10 & 3.48 & 2.99 & $-14.9 \pm 0.3$ & $-29 \pm 1$ & $-6.36 \pm 0.2$ \\
\hline Et & 4.78 & 4.08 & 3.53 & 3.13 & $-14.0 \pm 0.2$ & $-26 \pm 1$ & $-6.36 \pm 0.1$ \\
\hline $\operatorname{Pr}$ & 4.53 & 3.91 & 3.42 & 3.01 & $-13.6 \pm 0.1$ & $-25 \pm 1$ & $-6.24 \pm 0.2$ \\
\hline $\operatorname{Pr}^{\mathrm{i}}$ & 4.47 & 3.92 & 3.45 & 3.08 & $-12.6 \pm 0.1$ & $-22 \pm 1$ & $-6.20 \pm 0.2$ \\
\hline $\mathrm{ClCH}_{2}$ & 4.80 & 4.11 & 3.50 & 3.10 & $-14.5 \pm 0.2$ & $-28 \pm 1$ & $-6.38 \pm 0.2$ \\
\hline $\mathrm{MeCDO}$ & 4.65 & 4.11 & 3.53 & 3.00 & $-14.4 \pm 0.5$ & $-27 \pm 2$ & $-6.34 \pm 0.4$ \\
\hline
\end{tabular}

The dependence of $k_{\mathrm{obs}}$ on the concentration of aldehyde was studied at different temperatures and the

\begin{tabular}{|c|c|c|c|c|c|c|c|}
\hline \multirow{2}{*}{$\begin{array}{l}\text { Subst. } \\
\text { (R) }\end{array}$} & \multicolumn{4}{|c|}{$10^{3} k_{2} / \mathrm{s}^{-1}$} & \multirow{2}{*}{$\begin{array}{c}\Delta H^{*} \\
\mathrm{~kJ} \mathrm{~mol}^{-1}\end{array}$} & \multirow{2}{*}{$\begin{array}{c}\Delta S^{*} \\
\mathrm{~J} \mathrm{~mol}^{-1} \mathrm{~K}^{-1}\end{array}$} & \multirow{2}{*}{$\frac{\Delta G^{*}}{\mathrm{~kJ} \mathrm{~mol}^{-1}}$} \\
\hline & $298 \mathrm{~K}$ & $308 \mathrm{~K}$ & $318 \mathrm{~K}$ & $328 \mathrm{~K}$ & & & \\
\hline $\mathrm{H}$ & 1.42 & 3.82 & 8.69 & 20.2 & $68.9 \pm 0.7$ & $-69 \pm 2$ & $89.2 \pm 0.6$ \\
\hline $\mathrm{Me}$ & 21.0 & 49.2 & 105 & 230 & $62.0 \pm 0.5$ & $70 \pm 2$ & $88.3 \pm 0.4$ \\
\hline Et & 34.5 & 80.3 & 167 & 365 & $60.9 \pm 0.7$ & $69 \pm 2$ & $81.4 \pm 0.5$ \\
\hline $\operatorname{Pr}$ & 41.5 & 98.3 & 202 & 438 & $60.8 \pm 0.8$ & $68 \pm 2$ & $80.9 \pm 0.6$ \\
\hline $\operatorname{Pr}^{\mathrm{i}}$ & 60.0 & 148 & 290 & 622 & $59.9 \pm 1.2$ & $67 \pm 4$ & $79.9 \pm 1.0$ \\
\hline $\mathrm{ClCH}_{2}$ & 0.062 & 0.176 & 0.432 & 1.14 & $75.7 \pm 0.9$ & $72 \pm 3$ & $97.0 \pm 0.7$ \\
\hline $\mathrm{MeCDO}$ & 3.30 & 8.30 & 18.6 & 42.5 & $66.3 \pm 0.5$ & $70 \pm 2$ & $87.2 \pm 0.4$ \\
\hline$k_{\mathrm{H}} / k_{\mathrm{D}}$ & 6.36 & 5.93 & 5.65 & 5.41 & & & \\
\hline
\end{tabular}
values of $K$ and $k_{2}$ were evaluated from the double reciprocal plots using equation (5). The thermodynamic

Table 3. Formation constants and thermodynamic parameters for RCHO-BIDC complexes

Table 4. Rates of decomposition and activation parameters for RCHO-BIDC complexes 
Table 5. Dependence of reaction rates of aldehydes (RCHO) on the hydrogen-ion concentration ${ }^{(a)}$

\begin{tabular}{ccccccc}
\hline$\left[\mathrm{H}^{+}\right]$ & \multicolumn{5}{c}{$10^{3} k_{\mathrm{obs}} / \mathrm{s}^{-1}$} \\
\cline { 1 - 6 } $\mathrm{mol} \mathrm{dm}^{-3}$ & $\mathrm{H}$ & $\mathrm{Me}$ & $\mathrm{Et}$ & $\mathrm{Pr}$ & $\operatorname{Pr}^{\mathrm{i}}$ & $\mathrm{ClCH}_{2}$ \\
\cline { 2 - 6 } 0.1 & 0.121 & 1.55 & 2.24 & 2.66 & 4.07 & - \\
0.2 & 0.230 & 3.03 & 4.53 & 5.55 & 8.33 & 0.0110 \\
0.3 & 0.348 & 4.50 & 6.88 & 8.00 & 11.8 & 0.0155 \\
0.4 & 0.450 & 5.97 & 9.27 & 10.8 & 16.5 & 0.0232 \\
0.6 & 0.647 & 9.11 & 13.0 & 16.0 & 25.1 & 0.0309 \\
1.0 & 1.12 & 14.8 & 23.1 & 27.3 & 41.3 & 0.0514 \\
\hline
\end{tabular}

(a) [aldehyde] $=0.10 \mathrm{~mol} \mathrm{dm}^{-3},[\mathrm{BIDC}]=0.001 \mathrm{~mol} \mathrm{dm}^{-3}, T=308 \mathrm{~K}$.

parameters for the complex formation and the activation parameters for the decomposition of complexes were calculated from the values of $K$ and $k_{2}$ respectively, at different temperatures (Tables 3 and 4).

\section{Spectral Analysis}

A perusal of spectra of BIDC and BIDC + propionaldehyde showed that there is a distinct increase in the absorbance of BIDC by the addition of aldehyde (refer spectra [A] and [B]). This supports the formation of an intermediate complex. Further, the absorbance decreases with time and minimizes on about completion of reaction (refer spectra $[\mathrm{C}]$ and [D]). This indicates that the complex subsequently decomposes to give the ultimate product (Figure 3 ).

\section{Kinetic Isotope Effect}

To ascertain the importance of the cleavage of the aldehydic $\mathrm{C}-\mathrm{H}$ bond in the rate-determining step, the oxidation of deuteriated acetaldehyde (MeCDO) by BIDC was studied. The results (Tables 3 and 4) showed that the formation constants of the complexes of ordinary and deuteriated acetaldehyde are almost similar but the rates of their decomposition exhibited a substantial kinetic isotope effect $\left(k_{\mathrm{H}} / k_{\mathrm{D}}=6.36\right.$ at $\left.298 \mathrm{~K}\right)$.

\section{Effect of Acidity}

The rate of oxidation increases with an increase in acidity and the dependence is of the form - Rate $=k^{\prime}\left[\mathrm{H}^{+}\right]$ (Table 5). The order with respect to hydrogen ion is one. The log-log plot of $k_{\mathrm{obs}} v s .\left[\mathrm{H}^{+}\right]$, for all the aldehydes, showed that the slope $>0.95$ and $r^{2}>0.99$. The dependence of the reaction rate on the concentration of acetaldehyde was studied at three different concentrations of hydrogen-ion i.e. $\left[\mathrm{H}^{+}\right]=0.2,0.4$ and $1.0 \mathrm{~mol} \mathrm{dm}^{-3}$. It was observed that the formation constant, $K$, does not vary appreciably with the hydrogen-ion concentration, however, the rate of decomposition of complex increases linearly. Similar observations have been made in the oxidation of aldehydes ${ }^{11,12}$ and oxyacids of phosphorus ${ }^{13}$ by butyltriphenylphosphonium dichromate (BTPPD).

\section{Solvent Effect}

The oxidation of acetaldehyde by BIDC was studied in nineteen organic solvents. The solubility of the reactants and the reaction of BIDC with primary and secondary alcohols limited the choice of solvents. There was no reaction with the chosen solvents. The kinetics were similar in all the solvents. The corresponding values of $K$ and $k_{2}$, are recorded in Table 6 .

\section{DISCUSSION}

The entropies and enthalpies of activation of the oxidation of six aliphatic aldehydes do not exhibit satisfactory correlation $\left(r^{2}=0.6511\right)$. The correlation was tested and

Table 6. Effect of solvent on the oxidation of acetaldehyde by BIDC at $318 \mathrm{~K}$

\begin{tabular}{lcc}
\hline \multicolumn{1}{c}{ Solvent } & $K / \mathrm{dm}^{3} \mathrm{~mol}^{-1}$ & $10^{3} k_{2} / \mathrm{s}^{-1}$ \\
\hline Chloroform & 3.61 & 30.3 \\
1,2-Dichloroethane & 3.20 & 37.3 \\
Dichloromethane & 3.33 & 35.0 \\
DMSO & 3.48 & 105 \\
Acetone & 2.93 & 33.7 \\
Dimethylformamide & 3.01 & 55.5 \\
Butanone & 3.63 & 25.2 \\
Nitrobenzene & 2.89 & 42.0 \\
Benzene & 3.60 & 12.7 \\
Cyclohexane & 3.52 & 1.40 \\
Toluene & 2.91 & 10.5 \\
Acetophenone & 3.77 & 45.5 \\
Tetrahydrofurane & 3.86 & 18.0 \\
Tert-Butyl alcohol & 3.28 & 13.0 \\
Dioxane & 3.15 & 18.5 \\
1,2-Dimethoxyethane & 3.01 & 9.48 \\
Acetic acid & 2.87 & 5.51 \\
Ethyl acetate & 3.72 & 13.4 \\
Carbon disulfide & 3.81 & 5.30 \\
\hline & & \\
& &
\end{tabular}




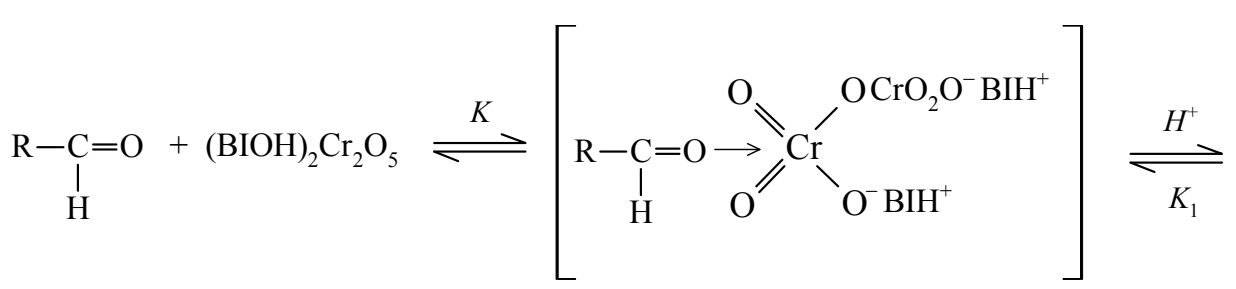
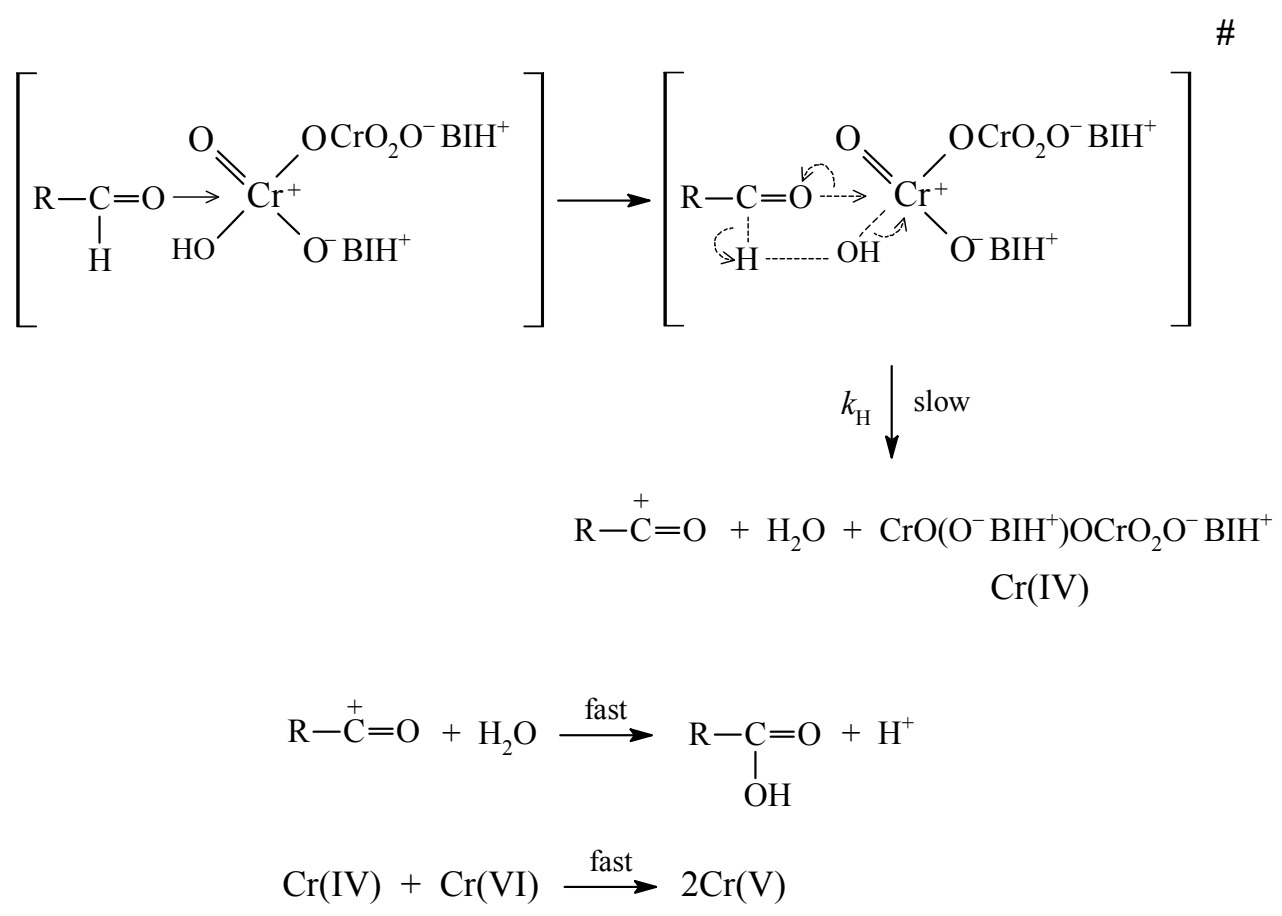

$\mathrm{Cr}(\mathrm{V})+$ reductant $\stackrel{\text { fast }}{\longrightarrow}$ product $+\mathrm{Cr}(\mathrm{III})$

$\mathrm{BI}=$ benzimidazole

Scheme 1.

found genuine by applying Exner's criterion. ${ }^{14}$ The Exner's plot between the values of $\log k_{2}$ at $298 \mathrm{~K}$ and at $328 \mathrm{~K}$, for the six aldehydes, is linear $\left(r^{2}=0.9998\right)$. The value of isokinetic temperature, determined by Exner's method, is $5821 \pm 317 \mathrm{~K}$. A linear isokinetic relationship is a necessary condition for the validity of linear free energy relationships. ${ }^{14}$ It also implies that all the reactions, so correlated, follow a similar mechanism.

BIDC seems to be an ionic compound as a result of proton transfer. To find out the state of BIDC in our reaction conditions, conductivity measurements have been carried out. It was observed that DMSO has very low conductivity and the addition of BIDC in DMSO shows negligible change in the conductivity value. Therefore, BIDC can be considered to be remained as non-ionised under our reaction conditions and does not dissociate as dichromate and benzimidazolium ions. No effect of added benzimidazolium ion on the rate of oxidation also supports the postulation that BIDC remain as nonionised. ${ }^{5}$ The crystal structure study of BIDC, reported by Meng et al. ${ }^{15}$ supports the non-ionic nature of the oxidant in the reaction system. The dichromate ion connects two benzimidazolium rings via. hydrogen bonds. With the effective hydrogen donor $(\mathrm{N}-\mathrm{H})$ and hydrogen acceptor $(\mathrm{O})$ in the molecule, BIDC forms a number of hydrogen bonds. Furthermore, an intermolecular hydrogen bridge is remarkably formed between two neighboured dichromate ions. The molecules are then linked into infinite chains by these hydrogen bridges which controlled the releasing process of 
dichromate ions to reaction system and thus the compound behaves as non-ionic in our reaction system. ${ }^{15}$

\section{Solvent Effect}

The data recorded in Table 6 indicate that the equilibrium constant, $K$, is fairly insensitive to the change in solvent, however, $k_{2}$, varies appreciably. Therefore, the values of the rate constant of the decomposition of complexes, $k_{2}$, in eighteen solvents $\left(\mathrm{CS}_{2}\right.$ was not considered as the complete range of the solvent parameters are not available), were correlated in terms of linear solvation energy relationship (LSER) of Kamlet et al. ${ }^{16}$ But the correlations were insignificant.

The data on solvent effect were then analysed in terms of Swain's ${ }^{17}$ equation (6), where A represents the anion-solvating power of the solvent and $\mathrm{B}$ the cationsolvating power; $\mathrm{C}$ is the intercept term, and $(\mathrm{A}+\mathrm{B})$ is postulated to represent the solvent polarity.

$$
\log k=a \mathrm{~A}+b \mathrm{~B}+\mathrm{C}
$$

The results of the correlation analyses in terms of Swain's equation, individually with $\mathrm{A}$ and $\mathrm{B}$, and with $(\mathrm{A}+\mathrm{B})$ are given below.

$$
\begin{aligned}
& \log k_{2}=0.52 \pm 0.01 \mathrm{~A}+1.67 \pm 0.01 \mathrm{~B}-2.96 \\
& R^{2}=0.9998, \mathrm{sd}=0.01, n=19, \Psi=0.01 \\
& \log k_{2}=0.28 \pm 0.55 \mathrm{~A}-1.81 \\
& r^{2}=0.0153, \mathrm{sd}=0.44, n=19, \Psi=1.02 \\
& \log k_{2}=1.63 \pm 0.09 \mathrm{~B}-2.79 \\
& r^{2}=0.9486, \mathrm{sd}=0.10, n=19, \Psi=0.23 \\
& \log k_{2}=1.29 \pm 0.15(\mathrm{~A}+\mathrm{B})-2.93 \\
& r^{2}=0.8190, \mathrm{sd}=0.19, n=19, \Psi=0.44
\end{aligned}
$$

The data on solvent effect showed an excellent correlation in terms of Swain's equation with both anion- and cation-solvating powers contributing to the observed solvent effect. However, the role of cationsolvation is major. It alone accounts for $c a .95 \%$ of the data. The solvent polarity, represented by $(\mathrm{A}+\mathrm{B}) \mathrm{ac}-$ counted for $c a .82 \%$ of the data. In view of the fact $c a$. $82 \%$ of the data is accounted for by $(\mathrm{A}+\mathrm{B})$, an attempt was made to correlate the data with relative permittivity of the solvents. A plot of $\log k$ against the inverse of the relative permittivity, however, is not linear $\left(r^{2}=0.5023\right)$.

\section{Correlation Analysis of Reactivity}

The rates of oxidation of the six aldehydes show an excellent correlation with Taft's $\sigma^{*}$ substituent constant, ${ }^{18}$ the reaction constant being negative.

$$
\log k_{2}=\rho^{*} \sigma^{*}+\log k_{0}
$$

Here, $\rho^{*}$ measures the susceptibility of the reaction towards polar effects and $\mathrm{k}_{0}$ is the rate constant for acetaldehyde. The negative polar reaction constant indicates an electron-deficient carbon centre in the transition state of the rate-determining step. The reaction constant, $\rho^{*}$, for the oxidation of aldehydes were calculated at different temperatures (Table 7 ). The magnitude of the reaction constant decreases with an increase in temperature, indicating a decrease in the selectivity with an increase in temperature.

\section{Mechanism}

A one-electron oxidation, giving rise to free radicals, is unlikely in view of the failure to induce polymerisation of acrylonitrile. BHT is an excellent trap for free radicals. ${ }^{19}$ The fact that BHT was recovered unchanged also goes against the occurrence of a one-electron oxidation. The formation constants of the complexes of ordinary and deuterated acetaldehyde are almost similar, however, the rates of their decomposition exhibited a substantial kinetic isotope effect. This indicates that the aldehydic $\mathrm{C}-\mathrm{H}$ bond is cleaved in the rate-determining step. The negative values of the polar reaction constants point to an electron-deficient reaction centre in the transition state of the rate-determining step. This postulation is supported by the analyses of the solvent effect indicating much more contribution of the cation-solvation on the rate of decomposition of the complex. The order of reactivity also supports it. Therefore, the removal of hydrogen as hydride-ion resulting in an electrondeficient species in the rate-determining step, is indicated. However, the observed Michaelis-Menten type kinetics with respect to the aldehyde led us to suggest the formation of 1:1 complex by a nucleophilic attack of aldehydic oxygen on chromium in a rapid preequilibrium. The nature of the complex suggested is similar to that reported in the oxidation of aromatic aldehydes by PFC. ${ }^{20}$ The observed order of reactivity indicated that the electron-releasing groups accelerated the oxidation process. This is accounted in terms of an increase in the electron-availability at the oxygen of the aldehydic group resulting in the facilitation of the complex formation. The observed acid-dependence of the reaction points to a rapid reversible protonation of the intermediate complex prior to its disproportionation. A mechanism depicted in Scheme 1 accounts for the experimental results. The rate law based on the mechanism (Scheme 1) proposed can be written as-

$$
\text { Rate }=\frac{k_{\mathrm{H}} K_{1} K[\mathrm{BIDC}]_{t}[\text { Aldehyde }]\left[\mathrm{H}^{+}\right]}{1+K[\text { Aldehyde }]}
$$

Comparing equations (4) and (12), we get $k_{2}=k_{\mathrm{H}} K_{1}\left[\mathrm{H}^{+}\right]$ 
An analysis of the temperature dependence of the kinetic isotope effect by the method of Kwart and Nickle $^{21}$ showed that the loss of hydrogen proceeds through a concerted cyclic process. The data for protioand deuterio-acetaldehyde were fitted to the familiar expression

$$
k_{\mathrm{H}} / k_{\mathrm{D}}=A_{\mathrm{H}} / A_{\mathrm{D}} \exp \left(-\Delta E_{\mathrm{a}} / R T\right)
$$

or,

$$
\log \left(k_{\mathrm{H}} / k_{\mathrm{D}}\right)=\log \left(A_{\mathrm{H}} / A_{\mathrm{D}}\right)-\Delta E_{\mathrm{a}} / R T
$$

The results showed that the activation energy difference for $k_{\mathrm{H}} / k_{\mathrm{D}}$ is $4.36 \mathrm{~kJ}$ which agrees well with the zero-point energy difference for the respective $\mathrm{C}-\mathrm{H}$ and $\mathrm{C}-\mathrm{D}$ bonds $\left(c a .4 .30 \mathrm{~kJ} \mathrm{~mol}^{-1}\right)$ and the entropy of activation of the respective reactions are equal. This directly corresponds to the properties of a symmetrical transition state. $^{22,23}$ Similar phenomenon have been observed earlier in the oxidation of alcohols by BTPPD ${ }^{24}$ Bordwell $^{25}$ has given cogent evidence against the occurrence of concerted one-step bimolecular process of hydrogen transfer and it is clear that in the present reaction also, the hydrogen transfer does not occur by an acyclic bimolecular process. The only truly symmetrical processes involving linear transfer of hydrogen are intrinsically concerted sigmatropic reactions characterized by transfer with a cyclic transition state. ${ }^{26}$ The second step of the reaction was the transfer of two electrons in a cyclic system. This electrocyclic mechanism for the oxidation of aldehyde by BIDC involved six electrons, being a Hückel type system, is an allowed process. ${ }^{27}$ Therefore, one can safely conclude that in the oxidation of aldehyde by BIDC, the hydride-ion transfer occurs via a cyclic transition state. The manner of electron transfer has to be established. The first step involved the nucleophilic attack of aldehydic-oxygen electrons on electron-deficient chromium atom to form an intermediate complex. This complex then undergoes unimolecular decomposition in the slow step. The transition state involves the bonding of hydrogen atom to both the aldehydic-carbon and the $\mathrm{OH}$ group attached to chromium. The electron flow in a cyclic transition state has been considered assuming that the hydrogen atom is removed as hydride-ion. Thus, the process of electron transfer takes place through the carbon-hydrogenoxygen-chromium bond. This would facilitate the formation of a carbocationic species by reverting back the nucleophilic attack of aldehydic oxygen. The similar type of mechanism is reported for the oxidation of oxyacids by BTPPD. ${ }^{13}$

The proposed mechanism is, however, supported by the observed negative entropy of activation. As the charge separation takes place in the transition state, the
Table 7. Temperature dependence of the reaction constant

\begin{tabular}{ccccc}
\hline Temperature $/ \mathrm{K}$ & $\rho^{*}$ & $r^{2}(n)^{(\mathrm{a})}$ & $\mathrm{sd}$ & $\Psi$ \\
\hline 298 & $2.40 \pm 0.02$ & $0.9998(6)$ & 0.016 & 0.015 \\
308 & $2.34 \pm 0.02$ & $0.9996(6)$ & 0.026 & 0.022 \\
318 & $2.27 \pm 0.02$ & $0.9996(6)$ & 0.022 & 0.022 \\
328 & $2.20 \pm 0.02$ & $0.9998(6)$ & 0.017 & 0.015 \\
${ }^{(\mathrm{a})} n=$ number of data points. & & &
\end{tabular}

two ends become highly solvated. This results in an immobilization of a large number of solvent molecules, reflected in the loss of entropy. The negative activation entropy additionally accounts for the influence of solvent.

Initially $\mathrm{Cr}(\mathrm{VI})$ is reduced to $\mathrm{Cr}(\mathrm{IV})$. It is likely to react with another $\mathrm{Cr}(\mathrm{VI})$ to generate $\mathrm{Cr}(\mathrm{V})$ which is then reduced in a fast step to the ultimate product $\mathrm{Cr}(\mathrm{III})$. Such a sequence of reactions in $\mathrm{Cr}(\mathrm{VI})$ oxidations is well known. ${ }^{28}$

It is of interest to compare here the results of present reaction with the oxidation of aliphatic aldehydes by other $\mathrm{Cr}(\mathrm{VI})$ complexes viz. BTPPD,${ }^{11}$ benzyltriethyl-ammonium chlorochromate (BTEACC), ${ }^{29}$ pyridinium fluorochromate (PFC), ${ }^{6}$ pyridinium bromochromate (PBC), ${ }^{30}$ quinolinium fluorochromate (QFC), ${ }^{31}$ quinolinium dichromate (QDC), ${ }^{14}$ pyridinium chlorochromate $(\mathrm{PCC}){ }^{32}$ morpholinium chlorochromate $(\mathrm{MCC})^{33}$ and 2,2'-bipyridinium chlorochromate (BPCC). ${ }^{34}$ It is observed that all the above oxidation reactions are of first order with respect to $\mathrm{Cr}(\mathrm{VI})$ species, however, they differ in the order with respect to aldehyde. The dependence of rate on the aldehyde concentration in the case of QDC, PBC, PCC, QFC, BTEACC, MCC and $\mathrm{BPCC}$ is first order, it is less than one in the case of PFC and BIDC, whereas it is more than one but less than two for the oxidation by BTPPD. Thus, a Michaelis-Menten type kinetics were observed in the oxidation by BIDC, PFC and BTPPD. All the reactions are catalysed by hydrogen-ion but the dependence is not same all through. In the oxidation by PBC, MCC, QFC, BPCC and BTEACC the dependence is of form: Rate $=a+$ $b\left[\mathrm{H}^{+}\right]$, the oxidation by QDC and BIDC involves first order dependence on $\left[\mathrm{H}^{+}\right]$. However, it is of form: Rate $=k\left[\mathrm{H}^{+}\right]^{2}$ in the oxidation by BTPPD. The effect of $\left[\mathrm{H}^{+}\right]$ on rate in the case of PFC was not studied. All the reactions exhibited a substantial kinetic isotope effect. The results of solvent effect are of similar nature in all these reactions. The rate constants correlate well with Taft's $\sigma^{*}$ values in all the reactions, the reaction constants being negative. A similar kind of mechanisms involving a formation of protonated intermediate complex in a rapid pre-equilibrium which undergoes unimolecular decomposition in slow step via. hydride-ion transfer to give either carbocationic species or the final product is 
postulated. The nature of complex is not same in all the oxidation reactions. In the oxidation by QDC, the reactive reducing species is aldehyde hydrate. Also, in the oxidation reactions of $\mathrm{PBC}, \mathrm{MCC}, \mathrm{QFC}, \mathrm{BPCC}$ and BTEACC an acid-independent path is also operative in addition to acid-dependant path. Thus, it is observed that the kinetics and mechanism of the oxidation of aliphatic aldehydes depend on the nature of oxidant.

Acknowledgements. We thank University Grants Commission and Council of Scientific and Industrial Research, New Delhi, for their financial support

\section{REFERENCES}

1. E. J. Corey and W. J. Suggs, Tetrahedron Lett. 16 (1975) 26472650; M. N. Bhattacharjee M. N., M. K. Chaudhuri, H. S. Dasgupta, N. Roy, and D. T. Kathing, Synthesis (1982) 588-590.

2. M. Li and M. E. Johnson, Synth. Commun. 25 (1995) 533-537; H. Firouzabadi and A. Sharifi, Synthesis (1992) 999-1002; I.M. Baltroke, M. M. Sadeghi, N. Mahmoodi, and B. Kharmesh, Indian J. Chem. 36B (1997) 438.

3. Q. H. Meng, J. C. Feng, N. S. Bian, B. Leu, and C. C. Li, Synth. Commun. 28 (1998) 1097-1102.

4. D. Panday and S. Kothari, Oxid. Commun. 32 (2009) 371-382.

5. D. Panday and S. Kothari, Prog. React. Kinet. Mech. 34 (2009) 199-209.

6. A. Agarwal, K. Chowdhury, and K. K. Banerji, J. Chem. Res $(S)$ (1990) 86-87.

7. V. Sharma and K. K. Banerji, J. Chem. Res. (S) (1990) 340-341; (M) 3551-3574.

8. D. D. Perrin, W. L. Armarego, and D. R. Perrin, Purification of Laboratory Chemicals, II edition, Pergamon Press, Oxford, 1981, p.74.

9. R. T. Hall and W. E. Schaefer, Organic Analysis, Vol. 2, (Ed. J. Mitchell), Interscience, New York, 1954, p.55.

10. O. Exner, Collect. Czech. Chem. Commun. 31 (1966) 32223251.

11. K. M. Dilsha and S. Kothari, Oxid. Commun. 32 (2009) 874-883.
12. D. Pandey and S. Kothari, Prog. React. Kinet. Mech. 33 (2008) 293-311.

13. A. Kothari, S. Kothari, and K. K. Banerji, Oxid. Commun. 23, (2000), 93-101.

14. O. Exner, Prog. Phys.Org. Chem. 10 (1973) 411-482.

15. Q. Meng, W. Yan, S. Xu, and Huang D. J. Chem. Crystallog. 34 (2004) 333-336.

16. M. J. Kamlet, J. L. M. Abboud, M. H. Abraham, and R. W. Taft, J. Org. Chem. 48 (1983) 2877-2887 and references cited therein.

17. C. G. Swain, M. S. Swain, A. L. Powell, and S. Alumni, J. Am. Chem. Soc. 105 (1983) 502-513.

18. K. B. Wiberg, Physical Organic Chemistry, John Wiley \& Sons, New York, 1964, p.416.

19. D. Mohajer and S. Tangestaninejad, Tetrahedron Letts. 35 (1994) 945-948.

20. S. Agarwal, K. Chowdhury, and K. K. Banerji, J. Org. Chem. 56 (1991) 5111-5113.

21. H. Kwart and J. H. Nickle, J. Am. Chem. Soc. 95 (1973) 3394 3396.

22. H. Kwart and H. C. Latimer, J. Am. Chem. Soc. 93 (1971) 3770 3771 .

23. H. Kwart and J. Slutsky, J. Chem. Soc. Chem. Commun. (1972) 1182-1183.

24. A. Kothari, S. Kothari, and K. K. Banerji, Indian J. Chem., 44A (2005) 2039-2043.

25. F. G. Bordwell, Acc. Chem. Res. 5 (1974) 374-381.

26. R. B. Woodward and R. Hoffmann, Agnew. Chem., Int. Ed. Engl. 8 (1969) 781-853.

27. J. S. Littler, Tetrahedron 27 (1971) 81-91.

28. K.B. Wiberg and W.H. Richardson, Oxidation in Organic Chemistry, Vol. A, Academic Press, New York, 1965, p.69.

29. K. Chouhan, PTSRK P. Rao and P. K. Sharma, J. Indian Chem. Soc. 83 (2006) 191-194.

30. R. Khanchandani, P. K. Sharma, and K. K. Banerji, Indian J. Chem. 35A (1996) 576-579.

31. M. Khurana, P. K. Sharma, and K. K. Banerji, React. Kinet. Catal. Lett. 67 (1999) 341-344.

32. S. Saraswati, V. Sharma, and K. K. Banerji, Indian J. Chem. 40A (2001) 583-587.

33. N. Soni, V. Tiwari, S. Kumbhat, I. Shastri, and V. Sharma, J. Indian Chem. Soc. 85 (2008) 857-861.

34. V. Kumbhat, P. K. Sharma, and K. K. Banerji, Indian J. Chem. 39A (2000) 1169. 